\title{
Different Modes of Inhibition of Rat Gastric Mucosal 6-Keto-PGF $1 a$ Production by Indomethacin, Aspirin and Aminopyrine
}

\author{
Takashige NISHIKAWA, Yuichi TOMORI ${ }^{\text {? }}$, Sukehide YAMASHITA ${ }^{\text {? }}$ \\ and Shin-ichiro SHIMIZU \\ Department of Pharmacology and 'First Department of Oral and Maxillofacial Surgery. \\ Kagoshima University Dental School, Kagoshima 890. Japan
}

Accepted December 21, 1988

\begin{abstract}
The actions of aminopyrine on rat gastric mucosal cyclooxygenase activity in vitro were investigated and compared with those of the cyclooxygenase inhibitors indomethacin and aspirin. Aminopyrine is a phenyl-pyrazolone derivative with potent analgesic and antipyretic properties, but is weakly ulcerogenic, while indomethacin and aspirin are known to cause considerable ulcerogenesis. Aminopyrine was less potent in its ability to inhibit cyclooxygenase activity. The inhibition by all three drugs decreased with an increase in the substrate concentration. Pre-incubation with the enzymes greatly increased the inhibitory action of indomethacin and aspirin, but only slightly increased that of aminopyrine. The inhibitory action of aminopyrine was reversible, whereas those of indomethacin and aspirin were irreversible. These findings are discussed in relation to the low incidence of gastrointestinal irritation caused by aminopyrine.
\end{abstract}

Indomethacin, aspirin and many other nonsteroidal anti-inflammatory drugs (NSAIDs) have long been known to be ulcerogenic (1-3), particularly in conjunction with other factors such as stress (4), and have been known to be inhibitors of prostaglandin (PG) biosynthesis (5). Aminopyrine, a phenylpyrazolone derivative with analgesic and antipyretic properties, is as effective as aspirin and other NSAIDs in the therapy for acute rheumatic fever, and it is sometimes considered a superior anti-inflammatory agent bacause it causes less gastric irritation and ulcerogenesis, although its clinical use has declined due to its recently recognized bone marrow toxicity (6). PGs and $P G$ synthetase may be present in the gastrointestinal tract in relation to their physiological functions (710). The inhibitory effect of many NSAIDs on $P G$ biosynthesis causes ischemia of vascular beds, especially in areas already damaged by other factors $(5,11)$. Drugs which produce gastric mucosal ulceration or injury have been shown to reduce $\mathrm{H}^{+}$secretion $(12,13)$. Spenney and Mize (14) reported that indomethacin, aspirin and other NSAIDs enhanced the back-diffusion of $\mathrm{H}^{+}$through the mucosa, increased the loss of $\mathrm{H}^{+}$from the lumen, and consequently reduced $\mathrm{H}^{+}$secretion.

The analgesic, antipyretic and anti-inflammatory properties and the PG synthesisinhibiting activities of these drugs have been extensively studied, but little is known about the mechanisms underlying ulcerogenesis in the gastrointestinal tract. The present study compared the effects of aminopyrine. indomethacin and aspirin on rat gastric mucosal cyclooxygenase activity under various experimental conditions in order to try to establish the mechanisms of ulcerogenesis.

\section{Materials and Methods}

Preparation of enzyme: Male Wistar rats weighing $150-250 \mathrm{~g}$ were killed by exsanguination after a blow on the head. Following removal of their stomachs, mucosal sections were prepared by separating the overlying muscle by blistering (15). This procedure involved inserting the tip of a fine needle (26 gauge) between the muscle and mucosa and injecting $20 \mathrm{mM}$ Tris- $\mathrm{HCl}$ buffer $(\mathrm{pH} 7.4)$. The raised muscle layer was then 
carefully cut away. The parts of the mucosal membranes were gently homogenized (200 $\mathrm{rpm} / \mathrm{min}$ ) in a glass-Teflon homogenizer with ten volumes of $50 \mathrm{mM}$ potassium phosphate buffer $(\mathrm{pH} 7.4)$. All procedures were performed at $0-3^{\circ} \mathrm{C}$. The homogenates were used as the source of the enzyme (cyclooxygenase). The enzyme was incubated at $37^{\circ} \mathrm{C}$ for $6 \mathrm{~min}$, after which the enzyme activity was stopped by addition of $50 \mu \mathrm{l}$ of ice-cold $2 \mathrm{M}$ citric acid. The mixture was centrifuged at $20,000 \mathrm{~g}$ for $10 \mathrm{~min}$ at $0-3^{\circ} \mathrm{C}$ and then assessed for the production of 6 -keto-PGF $1 \alpha$ (the stable breakdown product of $P \mathrm{GI}_{2}$ ) using radioimmunoassay kits (16). The results were expressed as ng (6-keto-PGF $1 \alpha) /$ mg mucosal protein and as the percentage of inhibition of the control value. Mucosal protein concentration was determined by the method of Lowry et al. (17) with bovine serum albumin as a standard.

Reaction medium: Unless otherwise stated. determination of cyclooxygenase activity was carried out at $37^{\circ} \mathrm{C}$ in a $1-\mathrm{ml}$ reaction mixture of arachidonic acid $\left(2 \times 10^{-5} \mathrm{M}\right)$, enzymes (0.7 mg gastric mucosal protein $/ \mathrm{ml}$ ), hydroquinone $\left(4 \times 10^{-4} \mathrm{M}\right)$, glutathione $\left(5 \times 10^{-4}\right.$ $M)$, various concentrations of indomethacin. aspirin or aminopyrine, ethano! $(1.0 \%, \mathrm{v} / \mathrm{v})$ and potassium phosphate buffer $(50 \mathrm{mM}, \mathrm{pH}$ 7.4). The $\mathrm{pH}$ value of the incubation medium was always confirmed to be $\mathrm{pH} 7.4$ before the start of incubation or pre-incubation. Ethanol, used as a solvent for arachidonic acid and inhibitors, had no effect on the reaction at the final concentration $(2.0 \%, \mathrm{v} / \mathrm{v})$ employed.

Effects of indomethacin, aspirin and aminopyrine on cyclooxygenase activity under different experimental conditions: The inhibition of cyclooxygenase by indomethacin. aspirin and aminopyrine was studied under the following three incubation conditions:

a) Inhibitors (indomethacin, aspirin and aminopyrine) and arachidonic acid were simultaneously added to the medium, and the reaction was promptly started by adding the enzyme preparation at $37^{\circ} \mathrm{C}$ in the presence of the cofactors (hydroquinone and glutathione) without pre-incubation.

b) Inhibitors were pre-incubated with enzymes in phosphate buffer containing cofactors at $37^{\circ} \mathrm{C}$ for $2 \mathrm{~min}$, and the reaction was started by adding 1 to 5 volumes of phosphate buffer containing arachidonic acid and cofactors at $37^{\circ} \mathrm{C}$; i.e., the concentration of inhibitors in the reaction medium was diluted to $1 / 2-1 / 6$ of that in the pre-incubation medium.

c) Inhibitors were pre-incubated with enzymes in phosphate buffer containing cofactors at $37^{\circ} \mathrm{C}$ for $2 \mathrm{~min}$, and the reaction was promptly started at $37^{\circ} \mathrm{C}$ with the cofactors.

Chemicals: The following drugs were used: 6 -keto-PGF $1 \alpha$ radioimmunoassay kits (NEN Research Product), arachidonic acid (Sigma, Grade 1; purity, approx. 99\%), hydroquinone (Merck), reduced glutathione (Sigma). indomethacin (Sigma), aspirin (Sigma) and aminopyrine (Sigma).

Statistical analysis: Statistical differences were analyzed by the unpaired Student's $t$ test. and linear regression analysis was done in some experiments. Data are presented as the mean \pm the standard error of the mean.

\section{Results}

Inhibitions of PG biosynthesis by indomethacin, aspirin and aminopyrine: The basal production of 6 -keto- $\mathrm{PGF}_{1 \alpha}$ was $2.8 \times$ $10^{-10}$ moles $/ \mathrm{min} / \mathrm{mg}$ gastric mucosal protein.

Various amounts of indomethacin, aspirin and aminopyrine were added to the incubation test tube, and the percentage inhibition of cyclooxygenase activity was determined.

All drugs tested inhibited the formation of PGs as shown in Fig. 1. As expected, the inhibitory action of indomethacin was markedly higher than those of aspirin and aminopyrine. The inhibitory potency of aminopyrine was less than that of aspirin. The IC50 values of indomethacin, aspirin and aminopyrine were caiculated to be $8.1 \times 10^{-7}$, $1.1 \times 10^{-3}$ and $3.8 \times 10^{-3} \mathrm{M}$. respectively. from the best fit curves $\left(r^{2}=0.91, r^{2}=0.90, r^{2}\right.$ $=0.90$, respectively) .

Effect of substrate concentration on inhibition of cyclooxygenase activity by drugs: Arachidonic acid at 5 to $80 \mu \mathrm{M}$ was added to the reaction mixture with the inhibitors, and the reaction was started by adding the enzyme preparation. Inhibitors were used at a fixed concentration of $1 \mathrm{C} 50$. The inhibitions of PG biosynthesis by indomethacin (8.1x 


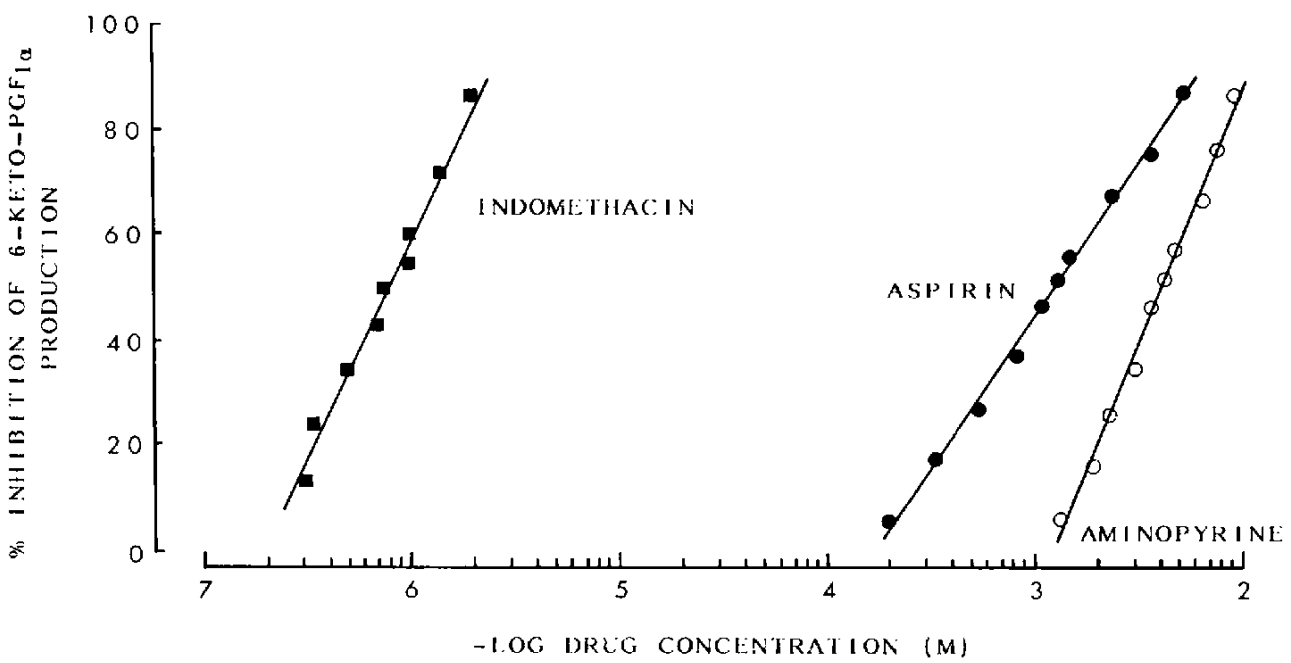

Fig. 1. Inhibition of rat gastric mucosal 6-keto-PGF ${ }_{1 a}$ production (cyclooxygenase) by indomethacin, aspirin and aminopyrine. The reaction media contained arachidonic acid $\left(8 \times 10^{-5} \mathrm{M}\right)$, hydroquinone $\left(4 \times 10^{-4} \mathrm{M}\right)$. glutathione $\left(5 \times 10^{-4} \mathrm{M}\right)$, various concentrations of inhibitors and $0.7 \mathrm{mg}$ mucosal protein in $1 \mathrm{ml}$ of $50 \mathrm{mM}$ potassium phosphate buffer $\left(\mathrm{pH} \mathrm{7.4)}\right.$. Incubation was carried out at $37^{\circ} \mathrm{C}$ for $6 \mathrm{~min}$. For details, see "Materials and Methods." Points are means for 4 to 8 determinations of different samples.

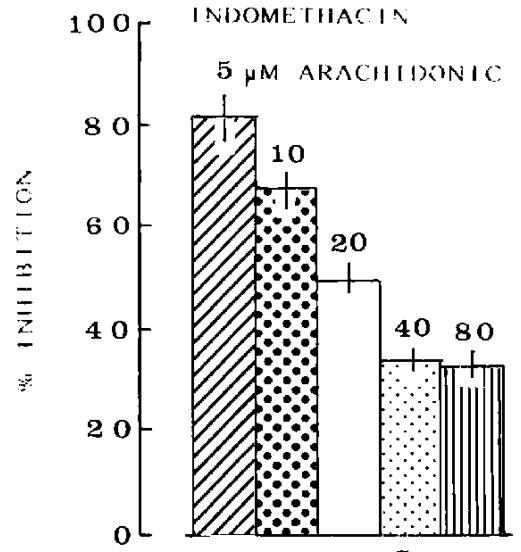

$8.1 \times 10^{-7} \mathrm{M}$ $\therefore S I^{2}$ IRIN

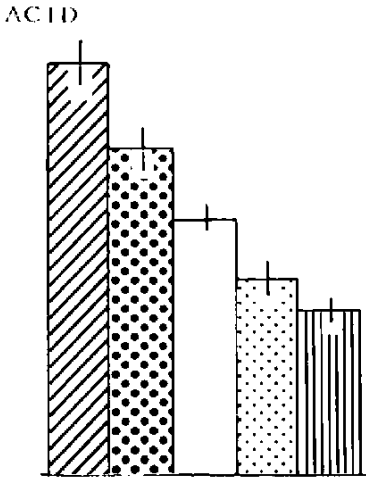

$1.1 \times 10^{-3} \mathrm{M}$
MMINOPYRINE

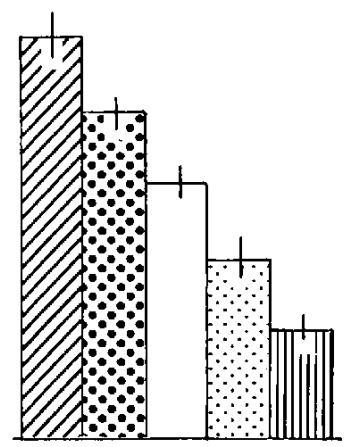

$3.8 \times 10^{-3}$

Fig. 2. Effects of substrate concentration on inhibition of 6 -keto-PGF a $_{a}$ production by indomethacin, aspirin and aminopyrine. The reaction medium contained various concentrations of arachidonic acid (5-80 $\mu \mathrm{M}$ ). hydroquinone, glutathione, inhibitor (indomethacin, $8.1 \times 10^{-7} \mathrm{M}$; aspirin, $1.1 \times 10^{-3} \mathrm{M}$; aminopyrine, $3.8 \times 10^{-3} \mathrm{M}$ ) and $0.7 \mathrm{mg}$ mucosal protein in $1 \mathrm{ml}$ of $50 \mathrm{mM}$ phosphate buffer. Incubation was carried out at $37^{\circ} \mathrm{C}$ for $6 \mathrm{~min}$. Columns represent mean values for 6 to 7 determinations with S.E.M. as a vertical line.

$\left.10^{-7} \mathrm{M}\right)$, aspirin $\left(1.1 \times 10^{-3} \mathrm{M}\right)$ and aminopyrine $\left(3.8 \times 10^{-3} \mathrm{M}\right)$ increased with a decrease in the arachidonic acid concentrations. At the highest concentration of substrate used $(80 \mu \mathrm{M})$, the inhibition levels by indomethacin, aspirin and aminopyrine were 33.2.
32.3 and $21.5 \%$, respectively. while at the lowest concentration of substrate $(5 \mu \mathrm{M})$, their inhibitions were 812.80 .2 and $78.8 \%$. respectively (Fig. 2). By Lineweaver-Burk plot analysis, the $K_{m}$ and $V_{\max }$ values were determined to be $5.0 \times 10^{-5} \mathrm{M}$ and $3.4 \times 10^{-10}$ 
$\mathrm{mole} / \mathrm{min} / \mathrm{mg}$ protein, respectively, in the absence of inhibitors. These three inhibitors appear to be competitive as our data on the Lineweaver-Burk plot yielded straight lines with an intercept at approximately $V_{\text {max }}$.

Effect of dilution of drugs on cyclooxygenase activity: All inhibitors (two different concentrations of inhibitors were used: IC50 and higher than 1C80) were pre-incubated with enzymes for $2 \mathrm{~min}$, and the reaction was started by adding 1 to 5 volumes of phosphate buffer containing arachidonic acid and cofactors. Consequently, the concentration of inhibitors in the reaction medium was $1 / 2-1 / 6$ of that in the pre-incubation medium. As shown in Fig. 3, when the reaction mixture was diluted, the inhibitory action by aminopyrine was reversed in proportion to the degree of dilution, but not those by indomethacin and aspirin. The effects of indomethacin $\left(2 \times 10^{-6}, 8.1 \times 10^{-7} \mathrm{M}\right)$ and aspirin $\left(3.3 \times 10^{-3}, 1.1 \times 10^{-3} \mathrm{M}\right)$ were not reversed until six-fold dilution, whereas the inhibition by aminopyrine $\left(9 \times 10^{-3}, 3.8 \times 10^{-3} \mathrm{M}\right)$ was almost fully reversed at five- to six-fold dilutions (see Fig. 3).

Effects of pre-incubation of cyclooxygenase with drugs: The inhibition of cyclooxygenase activity by inhibitors with or without pre-incubation was studied. Indomethacin. aspirin and aminopyrine (two different concentrations of inhibitors were used: IC50 and lower than 1C25) were added at the start of pre-incubation, and their inhibitory effects were compared with the effects without preincubation. As shown in Fig. 4, indomethacin and aspirin were markedly more inhibitory after pre-incubation with the enzymes for 2 min: without and with pre-incubation, 8.1 $\times 10^{-7} \mathrm{M}$ indomethacin caused 50 and $90 \%$ inhibition, respectively, and $4 \times 10^{-7} \mathrm{M}$ indomethacin caused 23 and $73 \%$ inhibition. respectivelv; $1.1 \times 10^{-3} \mathrm{M}$ aspirin caused 50 and $94 \%$ inhibition, and $4 \times 10^{-4} \mathrm{M}$ aspirin. 22 and $74 \%$ inhibition, respectively. Aminopyrine inhibition was only slightly increased by pre-incubation: without and with preincubation. $3.8 \times 10^{-3} \mathrm{M}$ aminopyrine caused 50 and $60 \%$ inhibition, respectively, and $2.1 \times$ $10^{-3} \mathrm{M}$ aminopyrine, 24 and $34 \%$, respectively.

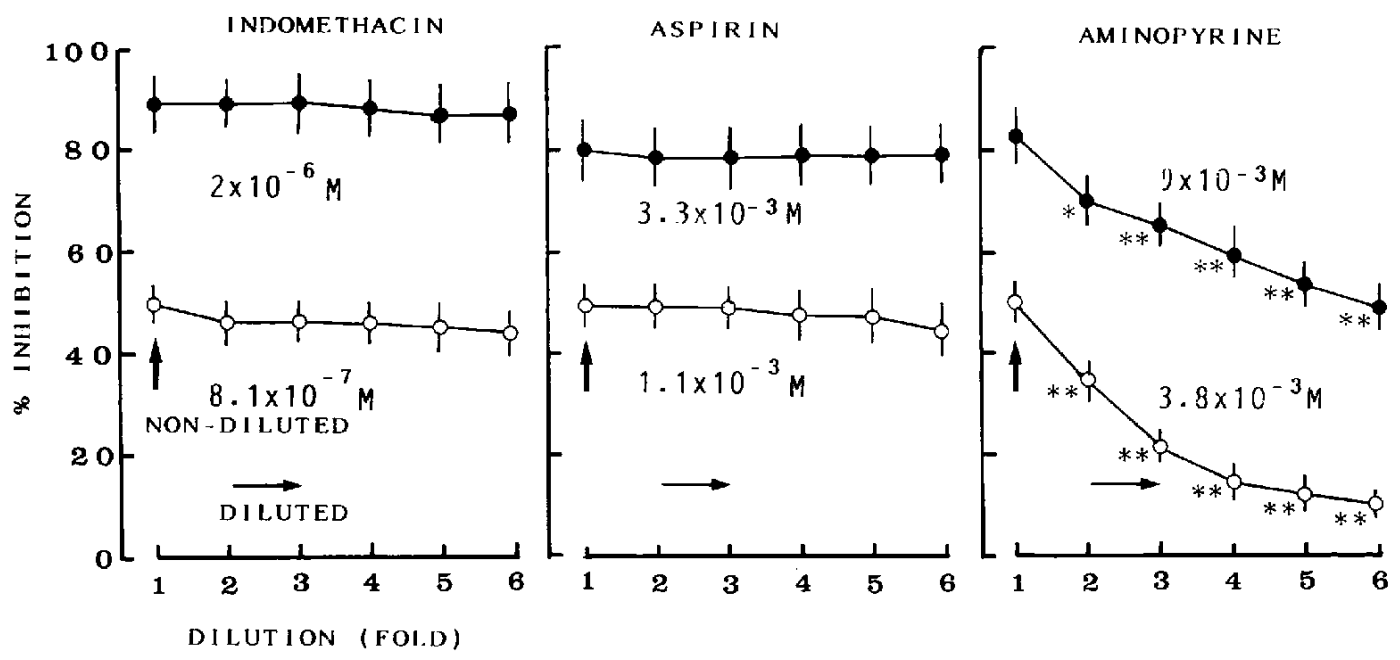

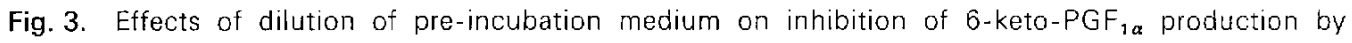
indomethacin, aspirin and aminopyrine. Inhibitors (indomethacin, $2 \times 10^{-6}, 8.1 \times 10^{-7} \mathrm{M}$; aspirin, $3.3 \times$ $10^{-3} .1 .1 \times 10^{-3} \mathrm{M}$; aminopyrine, $9 \times 10^{-3}, 3.8 \times 10^{-3} \mathrm{M}$ ) were pre-incubated with enzymes (0.7 mg protein $/ \mathrm{ml}$ ) in $50 \mathrm{mM}$ phosphate buffer containing hydroquinone and glutathione at $37^{\circ} \mathrm{C}$ for $2 \mathrm{~min}$, and the reaction was started by adding 1 to 5 volumes of $50 \mathrm{mM}$ phosphate buffer containing arachidonic acid, hydroquinone and glutathione at $37^{\circ} \mathrm{C}$ for $6 \mathrm{~min}$. Thus, the concentration of inhibitors in the reaction medium was $1 / 2-1 / 6$ of that in the pre-incubated medium. Points represent means \pm S.E.M. for 7 determinations. Significantly different from the response of the un-diluted sample, ${ }^{*} P<0.05,{ }^{* *} P<0.01$. 

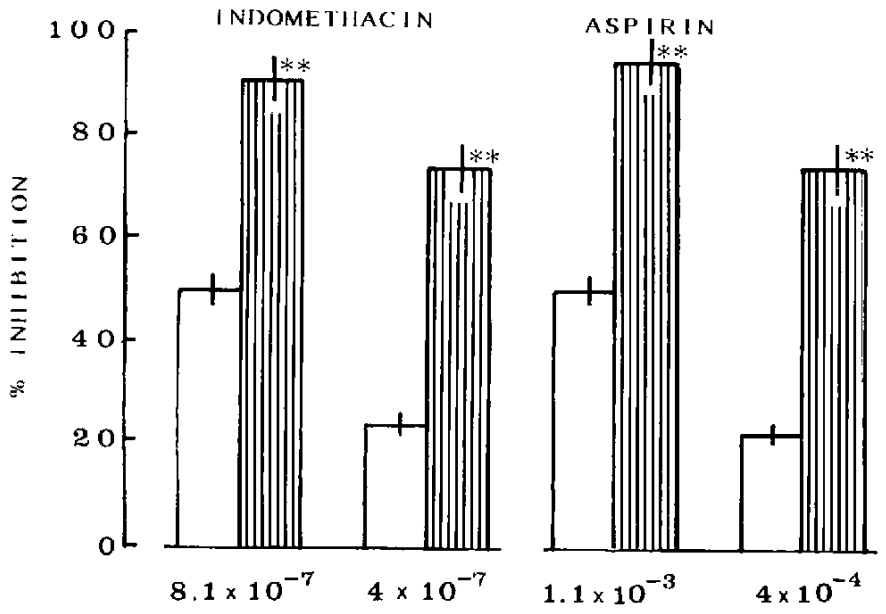

AMINOPYRINE

Fig. 4. Effects of pre-incubation of enzymes with indomethacin, aspirin and aminopyrine on 6-keto$\mathrm{PGF}_{1 \alpha}$ production. [ $\square$, no pre-incubation (substrate and inhibitors were simultaneously added to the incubation medium). I!ill'!.". pre-incubation (inhibitors were pre-incubated with enzymes at $37^{\circ} \mathrm{C}$, and 2 min later, substrate was added). The reaction media contained arachidonic acid, hydroquinone. glutathione, inhibitor (indomethacin. $8.1 \times 10^{-7}, 4 \times 10^{-7} \mathrm{M}$; aspirin, $1.1 \times 10^{-3}, 4 \times 10^{-4} \mathrm{M}$; aminopyrine, $3.8 \times$ $10^{-3}, 2.1 \times 10^{-3} \mathrm{M}$ ) and $0.7 \mathrm{mg}$ protein in $1 \mathrm{ml}$ of $50 \mathrm{mM}$ phosphate buffer. Incubation was carried out at $37^{\circ} \mathrm{C}$ for $6 \mathrm{~min}$. Columns represent means \pm S.E.M. for 5 to 7 determinations. Significantly different from response of the corresponding non-incubated sample, ${ }^{*} P<0.01,{ }^{* *} P<0.001$.

\section{Discussion}

The present results have shown that like indomethacin and aspirin, aminopyrine inhibited the rat gastric mucosal cyclooxygenase and the nature of the inhibition appears to be competitive. The order of inhibitory potency was indomethacin $\gg$ aspirin $>$ aminopyrine. Inhibitory effects of these drugs were similar to those reported by Flower (18) using a homogenate of sheep seminal vesicles, except that aspirin and aminopyrine were approximately equipotent in inhibiting cyclooxygenase activity. Several workers have already reported that indomethacin and aspirin or salicylate-like drugs are competitive inhibitors for PG synthetase $(6,18-21)$, although the mode of inhibition of aminopyrine has not yet been determined. The mechanism of the analgesic and antipyretic action of aminopyrine or its derivatives is still a matter of controversy (21-23).

The inhibitory activities of indomethacin and aspirin were greatly potentiated by preincubation with the enzymes and that of aminopyrine only slightly. Furthermore, the inhibitory actions of indomethacin and aspirin were not changed by dilution of the preincubation mixture, whereas the inhibition by aminopyrine was suppressed largely by dilution (see Fig. 3). Ku and Wasvary (24) and Lands and LeTellier (25) found that indomethacin and aspirin had the dual nature of so-called "competitive-irreversible" inhibition. According to this concept, indomethacin and aspirin may interact with a binding site sufficiently close to the active site to reduce the catalytic activity of the enzyme in a timedependent manner. On the other hand. aminopyrine inhibits it in a time-dependent but reversible manner. These results suggest that the in vivo effects of the reversible inhibitor aminopyrine, especially its inhibitory effect on the gastrointestinal tract, might be short-lasting. while that of indomethacin or aspirin might be long-lasting. In relation to this, Melarange and Rashbrook (10) recently compared the effects of nabumetone, 4-(6methoxy-2-naphthyl)-butane-2-one), which has a potent anti-inflammatory action, with indomethacin on rat gastric mucosal cyclooxygenase activity (production of 6-keto$P \mathrm{PF}_{1 \alpha}$ ) and suggested that nabumetone did not cause gastric damage because it had a 
minimal effect on gastric mucosal cyclooxygenase.

Natural and synthetic PGs have been shown to be potent inhibitors of gastric acid secretion and offer protection against peptic ulcers in animals and humans (26-31). PGinduced cytoprotective effects may involve increased blood flow $(32,33)$, bicarbonate secretion (34), mucus release (35), restoration of active sodium transport (36), decrease in back diffusion of acid or local stimulation of surface-active phospholipids (37), and maintenace of normal mucosal levels of DNA. RNA or protein (38). Furthermore, stress has been shown to decrease endogenous $P G$ formation in the rat mucosa and to augment peptic ulceration (39).

From our results and these findings, we suppose that the low incidence of gastrointestinal irritation due to aminopyrine, in comparison with other analgesics, might be related to its reversible effect (short-lasting) as well as to its lower inhibitory action on prostaglandin biosynthesis.

Acknowledgment: This work was supported in part by a Grant-in-Aid for Scientific Research from the Ministry of Education. Science and Culture, Japan.

\section{References}

1 Barbour, H.G. and Dickerson, V.C.: Gastric ulceration produced in rats by oral and sub. cutaneous aspirin. Arch. Int. Pharmacodyn. Ther. 58, 78-87 (1938)

2 Brown, P.A., Sawrey, J.M. and Vernikos, J.: Aspirin- and indomethacin-induced ulcers and their antagonism by antihistamines. Eur. J. Pharmacol. 51, 275-283 (1978)

3 Jick, H.: Effects of aspirin and acetaminophen in gastrointestinal hemorrhage. Results from the Boston Collaborative Drug Surveillance Program. Arch. Intern. Med. 141, 316-321 (1981)

4 Brown, P.A., Brown, T.H. and Vernikos-Danellis, J.: Histamine $\mathrm{H}_{2}$ receptor: Involvement in gastric ulceration. Life Sci. 18, 339-343 (1976)

5 Bennett, A., Stanford, I.F. and Unger, W.G.: Prostaglandin $E_{2}$ and gastric acid secretion in man. J. Physiol. (Lond.) 229, 349-360 (1973)

6 Flower, R.J., Moncada, S. and Vane, J.R.: Drug therapy of inflammation: Analgesic-antipyretics and anti-inflammatory agents: drugs employed in the treatment of gout. In The Pharmacological Basis of Therapeutics, Edited by Gilman. A.G.,
Goodman, L.S., Rall, T.W. and Murad. F., 7th Ed., p. 674-715, Macmillan, New York (1985)

7 Bennett, A. and Fleshler, B.: Prostaglandins and gastrointestinal tract. Gastroenterology 59, 790$800(1970)$

8 Splawinski, J.A., Nies, A.S., Sweetman, B. and Oates, J.A.: The effects of arachidonic acid, prostaglandin $E_{2}$ and prostaglandin $F_{2}$ alpha on the longitudinal stomach strip of the rat. J. Pharmacol. Exp. Ther. 187, 501-510 (1973)

9 Waller, S.L.: Prostaglandins and gastrointestinal tract. Gut 14, 402-417 (1973)

10 Melarange, R. and Rashbrook, L.C.: Comparison of the effects of nabumetone with indomethacin on rat gastric mucosal 6-keto-PGF ${ }_{1 \alpha}$ production and on bile salt-induced changes in gastric mucosal function. J. Pharm. Pharmacol. 39, 717-720 (1987)

11 Main, I.H.M. and Whittle, B.J.R.: Effect of indomethacin on rat gastric acid secretion and mucosal blood flow. Br. J. Pharmacol. 47, 666 (1973)

12 Davenport, H.W.: Damage to the gastric mucosa: Effects of salicylates and stimulation. Gastroenterology 49, 189-196 (1965)

13 Smith, J.B. and Willis, A.L.: Aspirin selectively inhibits prostaglandin production in human platelets. Nature 231, 235-237 (1971)

14 Spenney, J.G. and Mize, K.S.: Inhibition of gastric K+ATPase by phenylbutazone and indomethacin. Biochem. Pharmacol. 26, 1241 1245 (1977)

15 Forte, J.G., Forte, T.M. and Machen, T.E.: Histamine-stimulated hydrogen ion secretion by in vitro piglet gastric mucosa. J. Physiol. (Lond.) 244, 15-31 (1975)

16 Melarange, R. and Rashbrook, L.C.: A rat gastric mucosal preparation for studying agents which affect the in vitro production of prostanoids. Prostaglandins Leukotrienes Med. 22, 89-100 (1986)

17 Lowry, O.H., Rosebrough, N.J., Farr, A.L. and Randall, R.J.: Protein measurement with the Folin phenol reagent. J. Biol. Chem. 193, 265275 (1951)

18 Flower, R.J.: Drugs which inhibit prostaglandin biosynthesis. Pharmacol. Rev. 26, 33-67 (1974)

$19 \mathrm{Ham}$, E.A., Cirillo, K.J., Zanetti, M., Shen, T.Y. and Kuehl, F.A.: Studies on mode of action of nonsteroidal antiinflammatory agents. In Prostaglandins in Cellular Biology. Edited by Ramwell. P.W. and Pharris. B.B., p. 345-352. Prenum Press, New York (1972)

20 Vigdahl, R.L. and Tukey, R.H.: Mechanism of action of novel anti-inflammatory drugs di- 
flumidone and R-805. Biochem. Pharmacol. 26, 307-311 (1976)

21 Dembinska-Kiek, A., Zmuda, A. and Krupinska, J.: Inhibition of prostaglandin synthetase by aspirin-like drugs in different microsomal preparation. Adv. Prostaglandin Thromboxane Leukotriene Res. 1, 99-103 (1976)

22 Nikolova, M., Stefanova, D., Nikolv, R. and Daleva, L.: Comparative pharmacological study of dipyrone (analgin) and acetylsalicylic acid: Analgesic effects. In Proceedings of Dipyrone Symposium Moscow. Edited by Ovtcharov. R. and Pola, W. p. 91-98, Schttarwer Verlag Press. Stuttgart (1980)

23 Lorenzetti, B.B. and Ferreira, S.H.: Mode of analgesic action of dipyrone: Direct antagonism of inflammatory hyperalgesia. Eur. J. Pharmacol. 114, 375-381 (1985)

$24 \mathrm{Ku}$, E.C. and Wasvary, J.M.: Inhibition of prostaglandin synthetase by Su-21524. Fed. Proc. 32, 803A (1973)

25 Lands, W.E.M. and LeTellier, P.R.: Inhibition of prostaglandin biosynthesis. In Advances in Biosciences, Edited by Bergstrom, S. and Bernard, S., Vol. 9, p. 15-28, Pergamon Press, Vieweg and Braunschweig (1973)

26 Karim, S.M.M., Carter, D.C., Bhana, D. and Ganesan, P.A.: Effect of orally administered prostaglandin $E_{2}$ and its 15 -methyl analogues on gastric secretion. Br. Med. J. 1, 143-146 (1973)

27 Dajani, E.Z., Driskill, D.R., Bianchi, R.G., Collins, P.W. and Pappo, R.: SC-29333: A potent inhibitor of canine gastric secretion. Am. J. Dig. Dis. 21, 1049-1057 (1976)

28 Kollberg, B. and Slezak, P.: The effect of prostaglandin $\mathrm{E}_{2}$ on duodenal ulcer healing. Prostaglandins 24, 527-536 (1982)

29 Ganginella, T.S., Müller, R.K.M., Witt, C.G., Rosen, P., Holland, G.W., Gallo-Torres, H. and Sullivan, A.C.: Inhibition of acid secretion and gastric lesions in rats by the prostanoid Ro 22 6923. J. Pharmacol. Exp. Ther. 232, 202-207 (1985)

30 Zucker, K.A., Zdon, M.J., Adrian, T.E., Ballantyne,
G.E. and Modlin, I.M.: Prostaglandin inhibition of acid is cAMP dependent. J. Surg. Res. 42, 513-520 (1987)

31 Tsai, B.S., Kessler, L.K., Butchko, G.M. and Bauer, R.F.: Effect of misoprostol on histaminestimulated acid secretion and cyclic AMP formation in isolated canine parietal cells. Dig. Dis. Sci. 32, 1010-1016 (1987)

32 Main, I.H.M. and Whittle, B.J.R.: The effects of $E$ and $A$ prostaglandins on gastric mucosal blood flow and acid secretion in the rat. Br. J. Pharmacol. 49, 428-436 (1973)

33 Englert, E., Freston, J.W., Jr., Graham, D.Y. Finkelstein, W., Kruss, D.M., Priest, R.J., Raskin, J.B., Rhodes, J.B., Rogers, A.l., Wenger, J., Wilcox, L.L. and Crossley, R.J.: Cimetidine, antacid, and hospitalization in the treatment of benign gastric ulcer-A multicenter double blind study. Gastroenterology 74, 416-425 (1978)

34 Miller, T.A.: The protective effects of prostaglandins against gastric mucosal damage: Current knowledge and proposed mechanisms. Am. J. Physiol. 245, G601-G623 (1983)

35 Allen, A. and Garner, A.: Mucus and bicarbonate secretion in the stomach and their possible role in mucosal protection. Gut 21, 249-262 (1980)

36 Chaudhury, T.K. and Jacobson, E.D.: Prostaglandin cytoprotection of gastric mucosa. Gastroenterology 74, 58-63 (1978)

37 Lichtenberger, L.M., Graziani, L.A., Dial, L.A., Butler, B.D. and Hills, B.A.: Role of surfaceactive phospholipids in gastric cytoprotection. Science 219, 1327-1329 (1983)

38 Domschke, S., Dembiński, A. and Domschke, W.: Partial prevention of ethanol damage of human gastroduodenal mucosa by prostaglandin $E_{2}$ in vivo. Scand. J. Gastroenterol. 18, 113-116 (1983)

39 Basso, N., Materia, A., Forlini, A., Rossi, P. and Jaffe, B.M.: Gastric mucosal prostaglandin generation in rats with stress ulcer. Adv. Prostaglandin Thromboxane Leukotriene Res. 12, 383-387 (1983) 